Int. J. Dev. Biol. 57: 509-515 (2013)

doi: $10.1387 / \mathrm{ijdb} .120254 \mathrm{pm}$

\title{
Transgenes and their contributions to epigenetic research
}

\author{
PETER MEYER* \\ Center for Plant Sciences, University of Leeds, UK
}

\begin{abstract}
Shortly after gene transfer technologies had been established for different plant species, the first reports emerged about transgenes showing unexpected segregation patterns due to unstable expression. Initially, the erratic expression behavior of transgenes was considered a nuisance that impeded the impact and efficiency of a new technology. With the investigation of transgene silencing effects, however, it soon became clear that transgenes had helped us in a rather unexpected way to identify novel molecular pathways that were highly relevant to plant development and evolution. This article gives an account of a journey that started with the analysis of transgenerelated silencing events and that led to the discovery of a new molecular world of small RNAs and epigenetic marks that regulate plant gene expression and adaptation to environmental changes.
\end{abstract}

KEY WORDS: epigenetics, gene silencing, DNA methylation, small RNAs

\section{Introduction}

Curiosity has always been a major driver in science, and the desire to explain a bizarre, unexpected observation has probably generated more valuable insight for scientists than the well-designed research programs that can predict the outcome of research beforehand. The elucidation of epigenetic mechanisms is a prime example of the power of curiosity-driven research. When the first transgenic plants were produced, expectations were high for a new technology that would allow us to replace the historically successful but rather uncontrolled screens for best performing crop mutants with a more sophisticated and targeted design of novel transgenic traits. Despite the delays due to widespread scepticism about the usefulness of genetic engineering in modern agriculture, mainly in countries that benefit from affordable food supply, these prospects have been fulfilled as transgenic crops have become valuable components in a race that aims to match food supply with increasing demands for environmentally friendly and efficient cultivation.

Along with the high hopes for the application of recombinant DNA technologies in agriculture, came an almost naive demand to focus on the quick and efficient implementation of the new technology. The first reports about unforeseen silencing effects of transgenes were therefore largely considered as malfunctions of a new technology that needed to be ironed out. I still recall the summary speech of a highly influential scientist at the end of a major conference. When he highlighted the amazing new developments that had been discussed throughout the week, he finally also addressed the gene silencing phenomena that had been presented in what the organisers had chosen to call the 'enigmatic session'.
Due to lack of time or interest, he only spent a few words on these aspects, stating that there had been some unanticipated observations about transgenes not being expressed as expected, but that he was very confident that we would soon fully understand what had gone wrong in these exceptional cases.

It turned out that these minor glitches in implementing a new technology alerted us to the presence of a so far unnoticed epigenetic network that was not only relevant to plants, but to all eukaryotes controlling gene expression, genome stability, developmental programs, response to biotic and abiotic stress, and many other functions. Transgenic plants made us aware of this network and they helped us to investigate the underlying mechanisms. This article aims to highlight the key questions and findings that completed the jigsaw puzzle to understand the reasons behind transgene silencing and its wider implications.

With the benefit of hindsight over 30 years of research, it seems almost obvious that transgenes can come under epigenetic influences. To understand the significance of contributions that transgene research had made toward epigenetic effects, it will be useful to first illustrate the basic features of transcriptional gene silencing (TGS) (Fig. 1) and posttranscriptional gene silencing (PTGS) (Fig. 2) as we know them today. Initiated by small RNA breakdown products of double stranded (ds) transcripts, in both pathways DICER-like (DCL) RNAses cleave dsRNA and RNA-dependent

\footnotetext{
Abbreviations used in this paper: DCL, DICER-Like; RdDM, RNA-directed DNA methylation; RdRP, RNA-dependent RNA polymerase; PTGS, posttranscriptional gene silencing; PSTV, potato spindle tuber viroid; siRNA, small interfering RNA; TGS, transcriptional gene silencing.
}

\footnotetext{
*Address correspondence to: Peter Meyer. Centre for Plant Sciences, Faculty of Biological Sciences, University of Leeds, Miall 9.05, Leeds LS2 9JT, UK. Tel: +44 11334 33099; Fax: +44 11334 33144. p.meyer@leeds.ac.uk
}

Final, author-corrected PDF published online: 16 October 2013.

ISSN: Online 1696-3547, Print 0214-6282 
RNA polymerases (RdRPs) synthesize dsRNA targets. Small RNAs associate with Argonaute complexes that target DNA regions for TGS or homologous transcripts for degradation. The silencing pathways require helper functions that control small interfering (si) RNA stability, chromatin remodelling, RNA binding or unwinding, transcription or histone modification (Figs 1 and 2). Neither the concept of TGS mediated via epigenetic change nor the option of PTGS via transcript degradation or translational repression were known at the time when transgene silencing phenomena were first reported. This was not surprising, considering that we had no idea at that time about the regulatory role of small RNAs or the histone code. It took almost two decades to elucidate the molecular effects behind the various gene silencing effects, and transgenic plants played a major part in many of the relevant experiments.

\section{Homology-based silencing}

An important step toward understanding epigenetic silencing was the discovery of transgene silencing due to the presence of two homologous copies (Matzke et al., 1989), based on the analysis of the interaction between two homologous promoters that were sequentially transferred into tobacco (Nicotiana tabacum) as parts of two T-DNA constructs. The promoter of one of these T-DNAs was methylated and the transgene was silenced in plants that also contained the secondT-DNAconstruct with a homologous promoter. In addition to the promoter, the two T-DNAs shared substantial homology near the T-DNA border. The role of DNA methylation in preventing gene expression had already been noticed from the analysis of crown gall tumours that displayed heritable silencing of all or some hormone-producing genes, which could be reversed by treatment with the demethylation agent 5-azacytidine (Hepburn et al., 1983). Thus, transgene silencing was demonstrated to depend on the presence of a second homologous copy (Matzke et al., 1989).
In accordance with this model, silencing was reversed when the second T-DNA copy was segregated away, but methylation and silencing were not changed by the 5-azacytidine treatment. The discovery that the presence of homologous copies favoured DNA methylation also helped to explain another puzzling observation reported by several laboratories within the previous two years. While many transgenic plants transmitted transgenes to the next generation in a Mendelian fashion, a lower than expected transmission rate had been noticed on several occasions, which often correlated with the presence of multiple transgene copies (Deroles and Gardner, 1988).

\section{Post-transcriptional gene silencing (PTGS)}

In 1990, two publications highlighted that homology-dependent silencing was not restricted to transgenes. Indeed, they demonstrated that an endogenous gene could be switched off when a plant was transformed with another gene copy. The transfer of sense transgenes originally served as a negative control for experiments that aimed to demonstrate how genes can be inactivated by expressing antisense transgenes, a strategy that had been very successful in bacteria. When the floral pigmentation pathway genes dihydroflavonol-4-reductase (DFR) or chalcone synthase $A(c h s A)$ in petunia (Petunia hybrida) were expressed, a large proportion of the transformants had partially or completely lost the activity of the transgene and the corresponding endogenous gene (Napoli et al., 1990; van der Krol et al., 1990). This 'cosuppression' phenomenon that was due to a dramatic reduction of steady-state mRNA levels of the transgene and homologous endogene, was reminiscent of paramutation effects reported for some alleles. Unlike paramutation, however, cosuppression depended on the presence of the transgene because the silencing effect did not persist after segregation of the homologous copies (Napoli et al.,

\section{A}

Fig. 1. Schematic model of essential steps in transcriptional gene silencing. (A) SiRNA synthesis. The siRNA precursor dsRNA is generated by inverted repeat or antisense transcripts that are synthesized by Pol II (1) or by RDR2-reverse transcribing Pol IV transcripts (2); dsRNA precursor RNA is cleaved by DCL3; 24-nucleotide cleavage products (3) are stabilized by HEN1 methylation (4), and one siRNA strand is loaded onto the AGO4RISC or AGO6-RISC complexes. (B) siRNA-induced epigenetic change. Pol $V$ is imported into the nucleus (6) and recruited to methylated DNA (7); the RISC complex binds to Pol $V$ and to the Pol $V$ transcript (8); de novo DNA methyltransferase DRM2 is recruited to the region (9) and DNA methylation is followed by removal of active chromatin marks H4ac, H3K4me2/3, and Ub-H2B (10) and by H3K9 methylation (11). The process is assisted by DNA binding functions (SSH1 and RDM1), chromatin remodelling factors (CLSY1, DRD1, and DMS3), transcriptional regulators (KTF1 and DMS4), RNA/DNA-binding proteins (IDN1, IDN2 and IDNL2), and histone modifier functions (SUV4/5/6, HDA6, JMJ14, and UBP26).
B

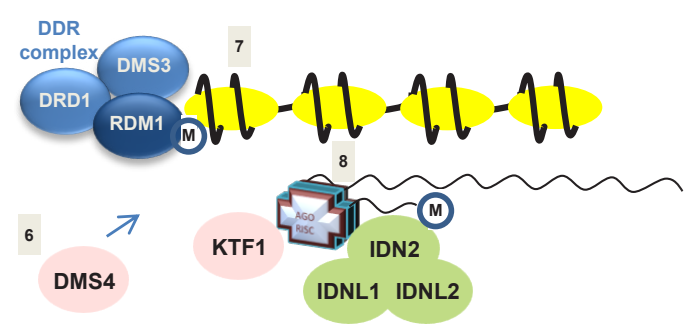


1990). In both publications, already the wider significance of the observations was noticed, because sector pigmentation in natural petunia varieties and semi-dominant effects of chs $A$ alleles in snapdragon (Antirrhinum majus) and maize (Zea mays) suggested that cosuppression was not a transgene-specific phenomenon. It took, however, more than a decade before tissue-specific silencing mechanisms of dominant chs $A$ copies were fully understood (Della Vedova et al., 2005; Koseki et al., 2005)

\section{The signal function of RNA}

As several reports had shown that transgene silencing was associated with DNA methylation in transgene promoter regions, which could be reverted via 5-azacytidine treatment, it was not surprising that the initial focus in explaining how homologous regions could favour transgene silencing was on the transfer of repressive DNA methylation patterns via association of homologous DNA regions. This picture changed with the first demonstration that that RNAwas the driving factor for the establishment of DNA methylation patterns (Wassenegger et al., 1994). DNA methylation in transgenic tobacco plants had been analyzed that carried a T-DNA containing a cDNA of the potato spindle tuber viroid (PSTV). PSTV infection, which caused autonomous viroid RNA replication in the nucleus, induced DNA methylation in the integrated T-DNA that was restricted to the PSTVd specific regions, implying that RNA had a guiding role in initiating de novo DNA methylation at homologous regions. In the absence of knowledge about small RNAs, DNA/RNA hybrids were proposed to play a role in generating a target for de novo methylation (Wassenegger et al., 1994). Interestingly, such a mechanism has recently been demonstrated for the methylation of rDNA loci

in mammals (Schmitz et al., 2010).

Further studies of chs $A$ cosuppression in petunia also identified mobile RNAs as the most likely candidates for the induction of cosuppression. Nuclear run-on analysis of chs $A$ transgene and endogene expression demonstrated that cosuppression was a posttranscriptional event. No correlation could be observed between transcript levels and the efficiency of cosuppression and even promoterless transgenes could induce cosuppression (Van Blokland et al., 1994). It therefore remained unclear whether transcription was actually required to induce cosuppression until cosuppression studies of nitrate reductase in tobacco revealed that transcriptional silencing of a PTGS-inducing transgene impeded cosuppression, demonstrating that the presence of transgene DNA alone could not induce PTGS (Vaucheret et al., 1997). Antisense transcripts, which were readily detected in cosuppression-showing tissues, or T-DNA loci that could pair with endogenous loci, were initially considered as potential factors involved in cosuppression (Van Blokland et al., 1994). These aberrant RNAs, especially the poly(A) 3 '-end chs $A$ fragments in cosuppressed tissues, suggested that degradation of $c h s A$ endogenes and transgene transcripts involved endonucleolytic cleavage at different positions, leaving behind defined, degradation-resistant RNA fragments. The same breakdown products were found in a natural petunia variety that contained red and white flower sectors, implying that $\operatorname{chs} A$ degradation was a transgene-independent process responsible for sectored coloration in some petunia varieties, but that could be enhanced by adding chs $A$ transgene copies. Again, no correlation between transgene transcript levels and the efficiency of co-suppression was observed, and a model was presented that involved the concept of transcript cleavage after pairing with an 'aberrant'homologous transcript and a role for dsRNA-specific RNase III was proposed (Metzlaff etal., 1997).

The argument that cosuppression or sense-silencing, as often referred to, was not a transgene-specific mechanism, had earlier also been supported by work with RNAviruses. Initial attempts to engineer virusresistant transgenic lines had been

Fig. 2. Schematic model of essential steps in PTGS. (A) siRNA synthesis and transcript degradation. siRNA precursor dsRNA is generated by inverted repeats (1), antisense transcripts (2), or by reverse transcription of aberrant $R N A$ (3) by RDR6, assisted by a putative RNA helicase (SDE3), an RNAseD exonuclease

B

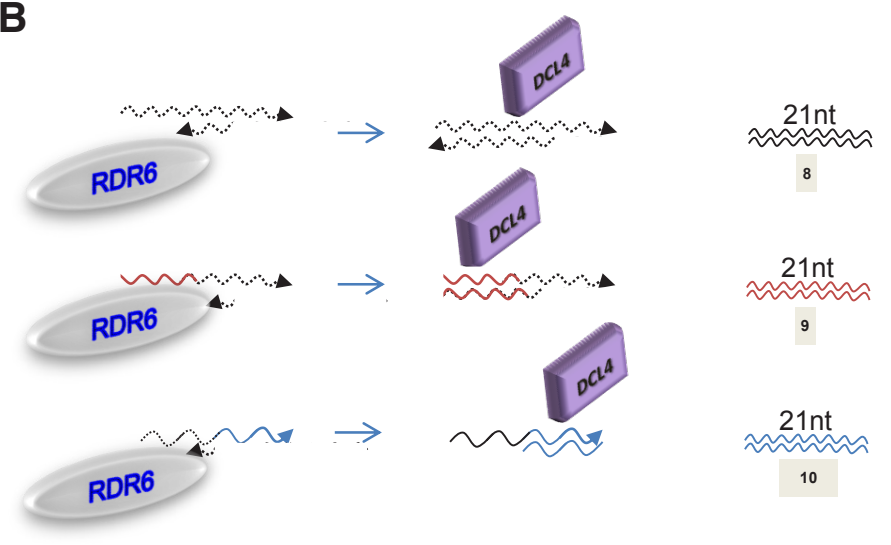
(WEX), and a coiled-coil protein of unknown function (SGS3). DCL4 cleaves dsRNA precursor RNA; the 21-nucleotide cleavage products (4) are stabilized by HEN1 methylation (5) and one siRNA strand is loaded onto the AGO1-RISC complex (6), which is guided to homologous transcripts that are degraded by the slicer activity of AGO1 (7). (B) siRNA amplification. SiRNAs are targeted to aberrant RNAs where they serve as primers for RDR6 to synthesize new dsRNA targets for DCL4, leading to a new pool of secondary siRNA that can represent the same regions as the primary siRNAs (8) or adjacent 5' regions (9) or 3' regions (10) of transcripts targeted by primary siRNAs, with transitive RNA silencing as a consequence. Dashed and full lines indicate regions homologous to the primary SiRNA pool and upstream (red) or downstream (blue) regions in transcripts that differ from the primary transcript sequence, respectively. 
dominated by concepts of viral antisense RNA expression or the synthesis of viral coat proteins. It became, however, soon apparent that even noncoding sense transcripts of viral genes could efficiently induce resistance to viral infection (Lindbo and Dougherty, 1992). Transgenic plants that expressed full or truncated copies of tobacco etch virus (TEV) coat protein transcripts and that had developed TEV resistance after TEV infection, contained surprisingly low steady-state levels of transgene RNA, whereas transcription rates were relatively high. This observation implied that viral infection induced a transcript breakdown mechanism in the transgenic plant. An RNA-dependent RNA polymerase (RdRP) had been suggested to amplify small RNA fragments that accumulated to high levels and would hybridize with homologous transcripts forming dsRNA targets for RNAses (Lindbo et al., 1993). The concept that transcript degradation was mediated by dsRNA formation was later supported by experiments that specifically engineered dsRNAs to target transcript degradation. Resistance to viral infection could be induced by transgenes that were able to produce dsRNAs with homology to a specific target virus, illustrating that RNA duplex formation was a key step in cosuppression (Waterhouse et al., 1998). The proposed role for an RdRP was confirmed for the first time in Neurospora crassa, in which, similar to plants, PTGS of an endogenous gene could be induced after the introduction of a homologous transgene via a mechanism, named quelling, reminiscent to cosuppression. The genetic power of the Neurospora system allowed for the efficient selection for quelling-resistant mutants. The first cloned quelling-resistance gene turned out to encode a protein with significant homology to plant and mammalian RdRPs, supporting the assumption that cosuppression and quelling are preserved silencing mechanism that have evolved to control the activity of viruses and transposons (Cogoni and Macino, 1999).

\section{Small RNAs}

By 1997, the role of RNA molecules as mobile mediators targeting homologous complementary transcripts for degradation or homologous DNA regions for methylation, had become a common feature in gene silencing models. The nature of these RNA molecules, however, remained obscure until yet another transgenic line provided the answer (Hamilton and Baulcombe, 1999). Analysis of three transgene-induced and one potato virus $X(P V X)$-induced PTGS events in tomato (Solanum lycopersicum) and tobacco revealed a common feature of all PTGS lines, namely the presence of approximately 25-nucleotide-long RNA fragments in antisense orientation to the introduced sense copy. As the antisense RNA could not be a breakdown product of the expressed sense transcripts and, at least in the PVX lines, no DNA template for antisense transcription was present, the antisense RNA was concluded to derive from reverse transcription of a sense RNA template by a RdRP. While it was still unclear whether the small antisense RNAs were synthesis or breakdown products, the potential role of small RNAs had been highlighted as mobile signals with target specificity (Hamilton and Baulcombe, 1999). Already two years previously, transgenic constructs had helped to identify a systemic gene silencing signal that moved from a local infiltration area into adjacent cells (Voinnet and Baulcombe, 1997) and to demonstrate target-specific, unidirectional transmission of a mobile signal from a silenced stock to a nonsilenced scion ( $\mathrm{Pa}$ lauqui et al., 1997). A series of grafting experiments with mutants of genes required for small RNA biogenesis finally established a long-range mobility of different classes of small RNAs that could induce epigenetic changes in target tissues (Molnar et al., 2010). A major biological consequence of these findings is that mobility of small RNAs and their potential amplification could transmit local signals to other sections of the plant, where they could induce epigenetic changes. If small RNAs were transported into pollen or sperm, this could mediate a transgenerational transmission of epigenetic changes induced in somatic tissues, for example in response to environmental stress (Molnar et al., 2010).

\section{Transcriptional gene silencing (TGS)}

DNA methylation of promoter regions was the first molecular modification associated with transcriptional transgene silencing. Early studies used DNA methylation-sensitive restriction enzymes to compare methylation patterns of active and silent genes in crown gall tumour lines or transformants. Gene inactivity was shown to correlate with hypermethylation (Amasino et al., 1984) and cytosines in CG and CNG contexts became methylated (Peerbolte et al., 1986). When the bisulfite sequencing technology became available, it was shown that cytosines in all sequence environments could be methylated (Meyer et al., 1994). This result contrasted the predominant methylation of cytosines in CG contexts in mammalian systems and highlighted that plants may have several DNA methylation systems with different target patterns. Another important feature of TGS that was revealed by transgenic plants was the association of DNA methylation with structural changes, because methylated and silenced transgenes showed a reduced sensitivity to endonucleases, reflecting an increased level of chromatin condensation (van Blokland et al., 1997). Hence, TGS might involve structural changes similar to heterochromatinization and DNA hypomethylation might be either the cause or the consequence of these structural changes. This hypothesis was very much in accordance with Barbara McClintock's concept for transposable elements, namely that changes in gene expression that were not due to changes in the genes themselves required a 'structural alteration in the chromatin materials' (McClintock, 1951). She had also predicted that changing environmental conditions can induce changes in nuclear components and, thus, in phenotypes. The responsiveness of transcriptionally silenced transgenes to environmental change at particular developmental phases was confirmed four decades later (Meyer et al., 1992), but the underlying mechanisms remained unclear. Although our understanding of TGS regulation has improved, we still encounter surprising results when the role of environmental signals is examined, as recently illustrated by the sharp changes in temperature that can temporarily override epigenetic regulation (Pecinka et al., 2010).

\section{Mutant screens for RNA-directed DNA methylation (RdDM) functions}

An important step toward the identification of components that regulate TGS and RNA-directed DNA methylation (RdDM) was the characterization of endogenous loci that showed changes in DNA methylation and produced distinct phenotypes in mutants or in antisense lines of maintenance DNA methyltransferase MET1 (Vongs et al., 1993). Especially the SUPERMAN (SUP) gene (Jacobsen and Meyerowitz, 1997) and the late-flowering gene FWA 
(Soppe et al., 2000) became useful loci to screen T-DNA insertion lines (Alonso et al., 2003) for changes in DNA methylation and gene expression. Transgenes again played an essential role in elucidating the rules of DNA methylation, because comparison of methylation patterns at the endogenous locus and at transgenic copies helped to differentiate between maintenance and de novo DNA methylation functions (Cao and Jacobsen, 2002). Following the identification of three DNA methyltransferases, the involvement of histone modification functions in RdDM became apparent when a HD6 histone deacetylase was found to be responsible for reactivation of a silent transgene (Aufsatz et al., 2002) and a screen for suppressors of RdDM at the SUP locus identified the histone H3 methyltransferase KRYPTONITE (KYP) (Jackson et al., 2002). As for PTGS, dsRNA plays a decisive role in the production of small RNAs that trigger TGS. This was demonstrated by expressing a transgene encoding a dsRNA homologous to a promoter region, which became efficiently methylated upon expression of the transgene (Mette et al., 2000). A green fluoresent protein construct with a promoter that had been silenced by dsRNA-induced RdDM, became a very powerful tool to identify RdDM-specific functions (Kanno et al., 2005) in combination with reverse genetic screens to analyze changes at endogenous RdDM targets (Onodera et al., 2005). These approaches have provided a comprehensive picture of the enzymatic steps and target specificities of RdDM (Fig. 1) and this collection is still growing (Moissiard et al., 2012) (Lorković et al., 2012).

\section{Exploiting the rules of transgene silencing}

The deeper understanding of the molecular rules of transgene silencing quickly led to novel strategies for efficient transgeneinduced gene silencing or for the prevention of transgene silencing. The RDR6-controlled amplification process after priming of homologous transcripts by small RNAs can lead to the synthesis of dsRNA from transcripts. When these transcripts contain other regions that do not match the primary small RNA, reverse transcription into these regions forms novel dsRNA segments 5' or 3' of the primary region to produce novel, secondary siRNA pools when cleaved by DCL enzymes (Fig. 2). Viral vectors (Vaistij et al., 2002) and transgene loci (Van Houdt et al., 2003) have been used to exploit this transitive silencing effect, to extend transcript degradation to novel targets, but also to spread DNA methylation along target genes. Inhibition of critical PTGS functions turned out to be a useful strategy to prevent silencing effects. Both in RNAdependent RNA polymerase 6 (rdr6) and suppressorofgene silencing 3 (sgs3) mutants, stable transgene expression levels could be achieved, while in transformants with wild-type background, only one in five plants showed stable and high transgene expression levels (Butaye et al., 2004).

\section{Outlook}

The last three decades have seen impressive progress in our understanding of epigenetic effects and mechanisms, and transgene technologies were vital for these achievements. It will, however, be important to remain open minded about alternatives and exceptions to the rules we have established so far. Although there is ample proof for a crucial role of small RNAs, cytosine methylation, and histone marks in TGS, alternative silencing mechanisms have been described. De novo DNA methylation of the repetitive DNA sequence element, for example, does require the cooperative activity of all three DNA methyltransferases, but is independent of the RdDM pathway (Singh et al., 2008). The transcriptional regulator MORPHEUS' MOLECULE1 (MOM1) silences its targets without significant changes in DNA or histone methylation (Mittelsten Scheid et al., 2002), and a subset of MOM1 target loci is silenced independent of the siRNA pathway (Nishimura et al., 2012). We should also be careful in proposing too readily that distinct genetic loci are subject to epigenetic regulation, when they fulfil some criteria associated with epigenetic control. The very fact that a gene overlaps with an antisense-encoding gene, for example, is no proof that antisense transcription actually regulates gene expression, unless the direct dependence of transcript profiles on siRNA or antisense transcript levels has been demonstrated. Even antagonistic changes in sense and antisense transcript levels are not necessarily an indicator for antisense-based gene regulation (Kunova et al., 2012). We should also consider that evolution has developed strategies that avoid epigenetic effects, for instance by preventing the generation of dsRNAvia spatial/temporal separation or processing of sense and antisense transcripts (Zubko et al., 2011).

We also should remember that the majority of data used to build mechanistic epigenetic models in plants, were obtained from experiments with Arabidopsis thaliana, a most useful, but also unusual, model system that does significantly differ from many crop species with respect to genome complexity and composition. We may therefore find that the epigenetic rules established in Arabidopsis may vary in some other plant species. For example, the inactivation of demethylation functions causes different effects in Arabidopsis and rice (Oryza sativa). In Arabidopsis, a triple mutant of the vegetatively expressed demethylases REPRESSOR OF SILENCING 1 (ROS1), DEMETER-LIKE 2 (DML2), and DML3 are phenotypically normal and transmitted to the next generation (Penterman et al., 2007), whereas in rice, which encodes six putative DNA demethylases, null mutants for one of four ROS orthologs, ROS1a, that is expressed in somatic tissue, but also in female and male gametophytes, are not transmitted to the next generation (Ono et al., 2012). We should therefore be prepared to face some surprises when the mechanisms and the biological effects of epigenetic enzymes and pathways are examined in different plant species.

Finally, it might be useful to remember that we were alerted to the presence of epigenetic networks by the unexpected performance of transgenic plants, at a time when some researchers were confident that they had reached a comprehensive level of understanding about how to produce transgenic plants. Recognition of the potential of this unexpected behaviour of transgenic plants required a considerable level of imagination and open-mindedness. A similar attitude should be maintained when we analyze the results of future epigenetic research - it would be disappointing if we only found what we expected to find.

\section{References}

ALONSO J M, STEPANOVAA N, LEISSE T J, KIM C J, CHEN H, SHINN P, STEVENSON D K, ZIMMERMAN J, BARAJAS P, et al. (2003). Genome-wide insertional mutagenesis of Arabidopsis thaliana. Science 301: 653-657 [Erratum Science 301: 1849].

AMASINO R M, POWELLALT, GORDON M P (1984). Changes in TDNA methylation and expression are associated with phenotypic variation and plant regeneration 
in a crown gall tumor line. Mol Gen Genet 197: 437-446.

AUFSATZ W, METTE M F, VAN DER WINDEN J, MATZKE M, MATZKE A J M (2002). HDA6, a putative histone deacetylase needed to enhance DNAmethylation induced by doublestranded RNA. EMBO J 21: 6832-6841.

BUTAYE K M J, GODERIS I J W M, WOUTERS P F J, PUES J MT G, DELAURÉ S L, BROEKAERT W F, DEPICKER A, CAMMUE B P A, DE BOLLE M F C (2004). Stable high-level transgene expression in Arabidopsis thaliana using gene silencing mutants and matrix attachment regions. Plant $J$ 39: 440-449.

CAO X, JACOBSEN S E (2002). Role of the Arabidopsis DRM methyltransferases in de novo DNA methylation and gene silencing. Curr Biol 12: 1138-1144.

COGONI C, MACINO G (1999). Gene silencing in Neurospora crassa requires a protein homologous to RNA-dependent RNA polymerase. Nature 399: 166-169.

DELLA VEDOVA C B, LORBIECKE R, KIRSCH H, SCHULTE M B, SCHEETS K, BORCHERT L M, SCHEFFLER B E, WIENAND U, CONE K C, BIRCHLER JA (2005). The dominant inhibitory chalcone synthase allele C2Idf (Inhibitor diffuse) from Zea mays (L.) acts via an endogenous RNA silencing mechanism. Genetics 170: 1989-2002.

DEROLES S C, GARDNER R C (1988). Analysis of the TDNA structure in a large number of transgenic petunias generated by Agrobacterium-mediated transformation. Plant Mol Biol 11: 365-377.

HAMILTON A J, BAULCOMBE D C (1999). A species of small antisense RNA in posttranscriptional gene silencing in plants. Science 286: 950-952.

HEPBURN A G, CLARKE L E, PEARSON L, WHITE J (1983). The role of cytosine methylation in the control of nopaline synthase gene expression in a plant tumor. J Mol Appl Genet 2: 315-329.

JACKSON J P, LINDROTH A M, CAO X, JACOBSEN S E (2002). Control of CpNpG DNA methylation by the KRYPTONITE histone H3 methyltransferase. Nature 416: 556-560.

JACOBSENSE, MEYEROWITZEM (1997). Hypermethylated SUPERMANepigenetic alleles in Arabidopsis. Science 277: 1100-1103.

KANNO T, HUETTELB, METTE M F, AUFSATZ W, JALIGOT E, DAXINGER L, KREIL D P, MATZKE M, MATZKE A J M (2005). Atypical RNA polymerase subunits required for RNA-directed DNA methylation. Nat Genet 37: 761-765.

KOSEKI M, GOTO K, MASUTAC, KANAZAWAA (2005). The startype color pattern in Petunia hybrida 'Red Star' Flowers is induced by sequence-specific degradation of chalcone synthase RNA. Plant Cell Physiol 46: 1879-1883.

KUNOVAA, ZUBKO E, MEYER P (2012). A pair of partially overlapping Arabidopsis genes with antagonistic circadian expression. Int J Plant Genomics 2012: Article ID 349527.

LINDBO JA, DOUGHERTYW G (1992). Untranslatable transcripts of the tobacco etch virus coat protein gene sequence can interfere with tobacco etch virus replication in transgenic plants and protoplasts. Virology 189: 725-733.

LINDBO J A, SILVAROSALES L, PROEBSTING W M, DOUGHERTY W G (1993). Induction of a highly specific antiviral state in transgenic plants: implications for regulation of gene expression and virus resistance. Plant Cell 5: 1749-1759.

LORKOVIĆ Z J, NAUMANN U, MATZKE A J M, MATZKE M (2012). Involvement of a GHKL ATPase in RNA-directed DNA methylation in Arabidopsis thaliana. Curr Biol 22: 933-938.

MATZKE MA, PRIMIG M, TRNOVSKY J, MATZKE A J M (1989). Reversible methylation and inactivation of marker genes in sequentially transformed tobacco plants. EMBO J 8: 643-649.

MCCLINTOCK B (1951). Chromosome organization and gene expression. Cold Spring Harbor Symp Quant Biol 16: 1347.

METTE M F, AUFSATZ W, VAN DER WINDEN J, MATZKE M A, MATZKE A J M (2000). Transcriptional silencing and promoter methylation triggered by doublestranded RNA. EMBO J 19: 5194-5201.

METZLAFF M, O'DELL M, HELLENS R, FLAVELL R B (2000). Developmentally and transgene regulated nuclear processing of primary transcripts of chalcone synthase $A$ in petunia. Plant $J$ 23: 63-72.

MEYER P, LINN F, HEIDMANN I, MEYERZAH, NIEDENHOF I, SAEDLER H (1992). Endogenous and environmental factors influence $35 \mathrm{~S}$ promoter methylation of a maize A1 gene construct in transgenic petunia and its colour phenotype. $\mathrm{Mol}$ Gen Genet 231: 345-352.

MEYERP, NIEDENHOF I, TEN LOHUISM (1994). Evidence for cytosine methylation of nonsymmetrical sequences in transgenic Petunia hybrida. EMBOJ 13:2084-2088.
MITTELSTEN SCHEID O, PROBST A V, AFSAR K, PASZKOWSKI J (2002). Two regulatory levels of transcriptional gene silencing in Arabidopsis. Proc Natl Acad Sci USA 99: 13659-13662.

MOISSIARD G, COKUS S J, CARY J, FENG S, BILLI A C, STROUD H, HUSMANN $D$, ZHAN Y, LAJOIE B R, PATTON MCCORD R, HALE C J, FENG W, MICHAELS S D, FRAND A R, PELLEGRINI M, DEKKER J, KIM J K, JACOBSEN S E (2012). MORC family ATPases required for heterochromatin condensation and gene silencing. Science 336: 1448-1451.

MOLNARA, MELNYKCW, BASSETTA, HARDCASTLE TJ, DUNN R, BAULCOMBE D C (2010). Small silencing RNAs in plants are mobile and direct epigenetic modification in recipient cells. Science 328: 872-875.

NAPOLI C, LEMIEUX C, JORGENSEN R (1990). Introduction of a chimeric chalcone synthase gene into petunia results in reversible co-suppression of homologous genes in trans. Plant Cell 2: 279-289.

NISHIMURA T, MOLINARD G, PETTY T J, BROGER L, GABUS C, HALAZONETIS T D, THORE S, PASZKOWSKI J (2012). Structural basis of transcriptional gene silencing mediated by Arabidopsis MOM1. PLoS Genet 8: e1002484.

ONO A, YAMAGUCHI K, FUKADATANAKA S, TERADA R, MITSUI T, IIDA S (2012). A null mutation of ROS1a for DNA demethylation in rice is not transmittable to progeny. Plant J 71: 564-574.

ONODERA Y, HAAG J R, REAM T, COSTA NUNES P, PONTES O, PIKAARD C S (2005). Plant nuclear RNA polymerase IV mediates siRNA and DNA methylationdependent heterochromatin formation. Cell 120: 613-622.

PALAUQUI JC, ELMAYAN T, POLLIEN JM, VAUCHERET H (1997). Systemic acquired silencing: transgene-specific posttranscriptional silencing is transmitted by grafting from silenced stocks to nonsilenced scions. EMBO J 16: 4738-4745.

PECINKAA, DINH H Q, BAUBEC T, ROSA M, LETTNER N, MITTELSTEN SCHEID $\mathrm{O}$ (2010). Epigenetic regulation of repetitive elements is attenuated by prolonged heat stress in Arabidopsis. Plant Cell 22: 3118-3129.

PEERBOLTE R, LEENHOUTS K, HOOYKAASVAN SLOGTEREN G M S, WULLEMS G J, SCHILPEROORT RA (1986). Clones from a shooty tobacco crown gall tumor II: irregular TDNA structures and organization, TDNA methylation and conditional expression of opine genes. Plant Mol Biol 7: 285-299.

PENTERMAN J, ZILBERMAN D, HUH J H, BALLINGER T, HENIKOFF S, FISCHER R L. (2007). DNA demethylation in the Arabidopsis genome. Proc Natl Acad Sci USA 104: 6752-6757.

SCHMITZKM, MAYER C, POSTEPSKAA, GRUMMTI. (2010). Interaction of noncoding RNA with the rDNA promoter mediates recruitment of DNMT3b and silencing of rRNA genes. Genes Dev 24: 2264-2269.

SINGH A, ZUBKO E, MEYER P. (2008). Cooperative activity of DNA methyltransferases for maintenance of symmetrical and non-symmetrical cytosine methylation in Arabidopsis thaliana. Plant J 56: 814-823.

SOPPE W J J, JACOBSEN S E, ALONSOBLANCO C, JACKSON J P, KAKUTANI T, KOORNNEEF M, PEETERS A J M (2000). The late flowering phenotype of fwa mutants is caused by gain-of-function epigenetic alleles of a homeodomain gene. Mol Cell 6: 791-802.

VAISTIJ F E, JONES L, BAULCOMBE D C (2002). Spreading of RNA targeting and DNA methylation in RNA silencing requires transcription of the target gene and a putative RNA-dependent RNA polymerase. Plant Cell 14: 857-867.

VAN BLOKLAND R, TEN LOHUIS M, MEYER P (1997). Condensation of chromatin in transcriptional regions of an inactivated plant transgene: evidence for an active role of transcription in gene silencing. Mol Gen Genet 257: 1-13.

VANBLOKLANDR, VANDER GEESTN, MOLJ N M, KOOTERJ M (1994). Transgenemediated suppression of chalcone synthase expression in Petunia hybrida results from an increase in RNA turnover. Plant J 6: 861-877.

VAN DER KROLAR, MUR LA, BELD M, MOL J N M, STUITJE A R (1990). Flavonoid genes in Petunia: addition of a limited number of gene copies may lead to a suppression of gene expression. Plant Cell 2: 291-299.

VAN HOUDT H, BLEYS A, DEPICKER A (2003). RNA target sequences promote spreading of RNA silencing. Plant Physiol 131: 245-253.

VAUCHERET H, NUSSAUME L, PALAUQUI JC, QUILLÉRÉ I, ELMAYAN T (1997) A transcriptionally active state is required for posttranscriptional silencing (cosuppression) of nitrate reductase host genes and transgenes. Plant Cel/9: 1495-1504.

VOINNET O, BAULCOMBE D C (1997). Systemic signalling in gene silencing. Nature 389: 553-553.

VONGS A, KAKUTANI T, MARTIENSSEN R A, RICHARDS E J (1993). Arabidopsis 
thaliana DNA methylation mutants. Science 260: 1926-1928.

WASSENEGGER M, HEIMES S, RIEDEL L, SÄNGER H L (1994). RNA-directed de novo methylation of genomic sequences in plants. Cell 76: 567-576.

WATERHOUSE P M, GRAHAM M W, WANG MB (1998). Virus resistance and gene silencing in plants can be induced by simultaneous expression of sense and antisense RNA. Proc Natl Acad Sci USA 95: 13959-13964.

ZUBKO E, KUNOVA A, MEYER P (2011). Sense and antisense transcripts of convergent gene pairs in Arabidopsis thaliana can share a common polyadenylation region. PLOS ONE 6: e16769.

\section{Further Related Reading, published previously in the Int. J. Dev. Biol.}

\section{Genome organization and epigenetic marks in mouse germinal vesicle oocytes}

Amelie Bonnet-Garnier, Prisca Feuerstein, Martine Chebrout, Renaud Fleurot, Habib-Ullah Jan, Pascale Debey and Nathalie Beaujean Int. J. Dev. Biol. (2012) 56: 877-887

DNA methylation reprogramming and DNA repair in the mouse zygote Konstantin Lepikhov, Mark Wossidlo, Julia Arand and Jörn Walter Int. J. Dev. Biol. (2010) 54: 1565-1574

Chromatin states of developmentally-regulated genes revealed by DNA and histone methylation patterns in zebrafish embryos

Leif C. Lindeman, Cecilia L. Winata, Håvard Aanes, Sinnakaruppan Mathavan, Peter Aleström and Philippe Collas

Int. J. Dev. Biol. (2010) 54: 803-813

Seed development and inheritance studies in apomictic maize-Tripsacum hybrids reveal barriers for the transfer of apomixis into sexual crops

Olivier Leblanc, Daniel Grimanelli, Martha Hernandez-Rodriguez, Pablo A. Galindo, Ana M. Soriano-Martinez and Enrico Perotti

Int. J. Dev. Biol. (2009) 53: 585-596

Interplay between DNA methylation, histone modification and chromatin remodeling in stem cells and during development

Kohta Ikegami, Jun Ohgane, Satoshi Tanaka, Shintaro Yagi, and Kunio Shiota

Int. J. Dev. Biol. (2009) 53: 203-214

5 yr ISI Impact Factor $(2011)=2.959$
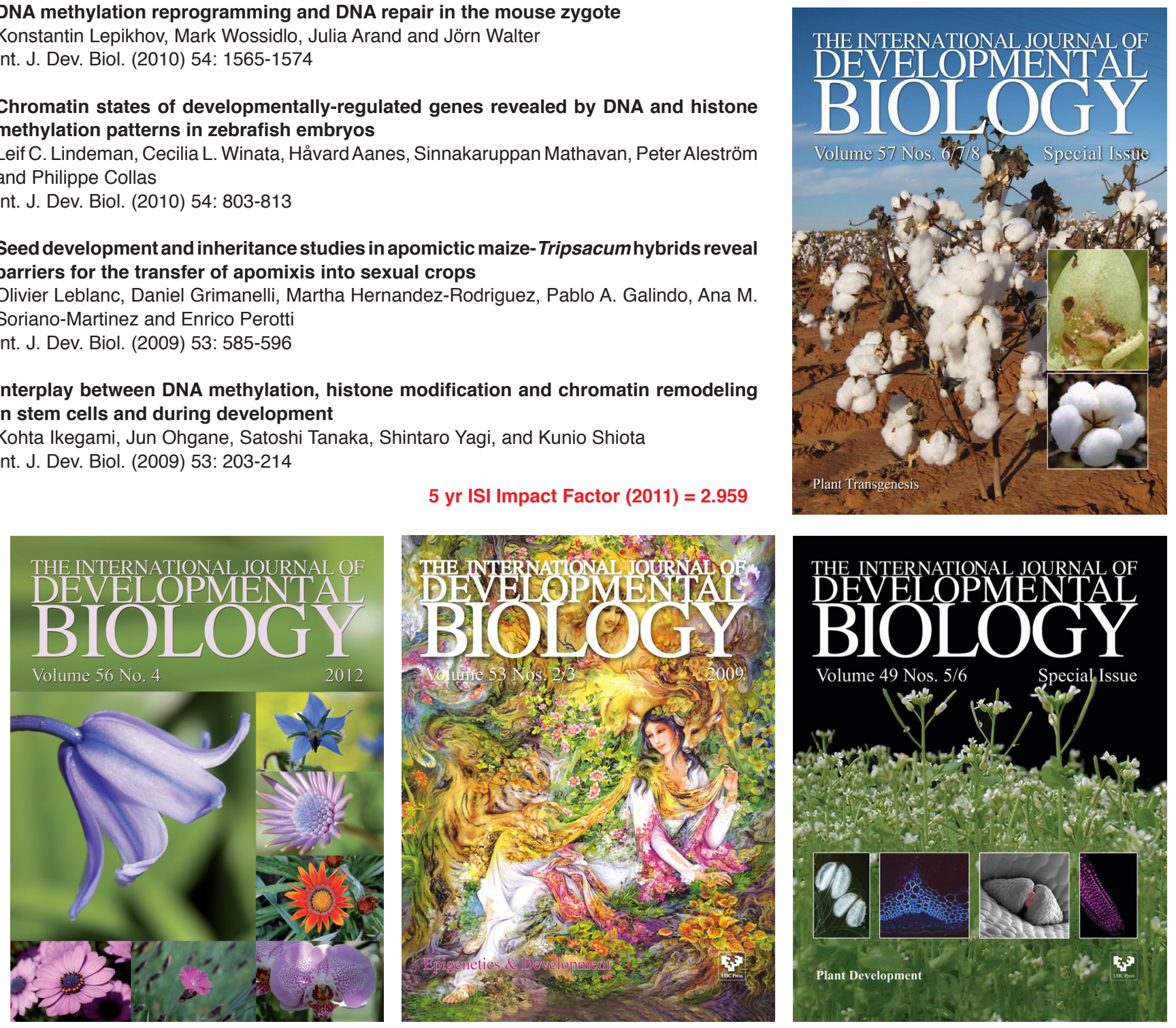